\title{
Corrigendum
}

\section{High-dose chemotherapy, autologous bone marrow or stem cell transplantation and post-transplant consolidation chemotherapy in patients with advanced breast cancer}

\author{
MS Tallman, AW Rademaker, L Jahnke, SG Brown, A Bauman, C Mangan, C Kelly, H Rubin,
} MS Kies, J Shaw, K Kiel, LI Gordon, WJ Gradishar and JN Winter

Bone Marrow Transplantation 1997; 20: 721-729

Since publication the author has noticed an error in Table 3 of the above paper. The heading 'No Post-transplant CSF' refers only to the first BM column and the heading 'Posttransplant CSF' refers to columns 2, 3 and 4 . A corrected version of Table 3 follows.

Table 3 Median number of days to engraftment of leukocytes and platelets according to post-transplant CSF support and source of progenitor cells

\begin{tabular}{lccccc}
\hline & No Post-transplant CSF & & Post-transplant CSF & All patients \\
\cline { 2 - 3 } & $B M(n=15)$ & $B M(n=15)$ & $P B P C(n=15)$ & $B M+P B P C(n=3)$ \\
ANC & 15 & $11^{\mathrm{b}}$ & $10^{\mathrm{b}}$ & 11 & 11.5 \\
Platelets & 22 & 14 & $12^{\mathrm{b}}$ & 10 & $14.5^{\mathrm{a}}$ \\
\hline
\end{tabular}

$\mathrm{ANC}=$ absolute neutrophil count; $\mathrm{BM}=$ bone marrow; $\mathrm{PBPC}=$ peripheral blood progenitor cells; CSF = colony-stimulating factor.

${ }^{\text {a} E x c l u d e s ~ o n e ~ p a t i e n t ~ w h o ~ d i e d ~ o n ~ d a y ~} 42$ of hemorrhage due to refractory thrombocytopenia despite trilineage engraftment and a second patient who developed PD at day 91 and had persistent thrombocytopenia requiring platelet transfusions (no marrow done at this time).

bignificantly different from no post-transplant CSF $(P<0.0083)$ 